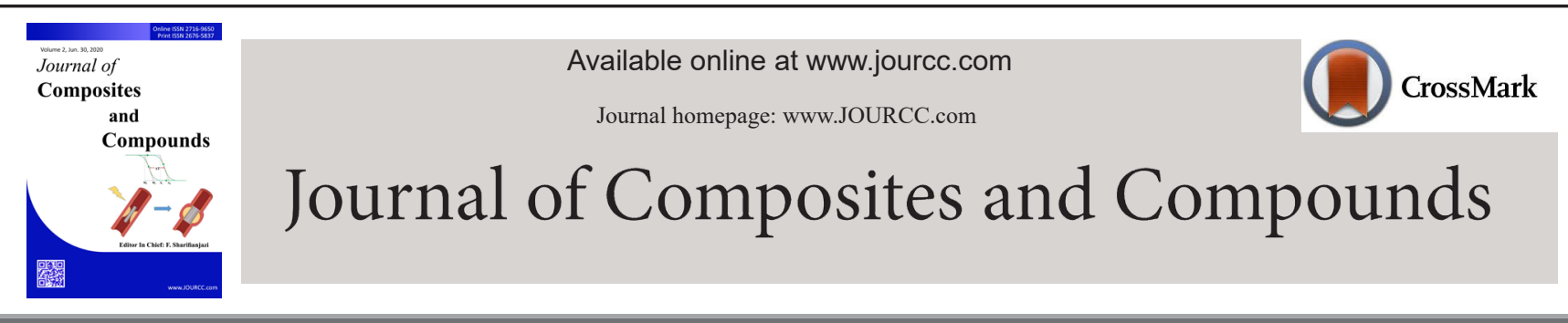

\title{
Synthesis of copper oxide nanoparticles on activated carbon for pollutant removal in tartrazine structure
}

\author{
Azadeh Jafari Rad ${ }^{a}$ * \\ a Department of Chemistry Omidiyeh Branch, Islamic Azad University (IAU), Omidiyeh, Iran
}

\begin{abstract}
A B S T R A C T
\end{abstract}
A R T I CLE IN F O R M A T I O N

In this study, activated carbon particles were modified by copper oxide to remove the anionic Tartrazine dye Article history:

from aqueous solutions. Adsorption studies were performed as batch studies and the influences of pH, initial dye Received 20 May 2020

concentrations, and contact times were evaluated. Maximum removal percentage was obtained for the initial con- Received in revised form 5 June 2020

centration of $30 \mathrm{mg} / \mathrm{L}$ and the equilibrium of the adsorption was achieved within 60 minutes of contact time. The Accepted 27 June 2020

Langmuir and Freundlich kinetic models were used for analyzing the equilibrium data. It was shown that better

fitting was observed by the Langmuir model. Pseudo-first-order and Pseudo-second-order kinetic models were Keywords:

also applied to understand the kinetics of the adsorption processes. It was found that the Tartrazine adsorption Tartrazine

followed the pseudo-second-order kinetic model.

(C)2020 JCC Research Group.

Activated carbon

Peer review under responsibility of JCC Research Group

Copper oxide

Removal efficiency

\section{Introduction}

The major environmental pollution source is the discharge of dye-containing wastewater from cosmetics, textiles, food, plastic, and paper industries [1-5]. These residual dyes present in the wastewater endanger the life of fish as well as other organisms. Moreover, these substances absorb sunshine resulting in photosynthesis prevention and an adverse impact on the natural aquatic ecosystem. As a result of their complex structure and high molecular weight, the degradation of organic dyes is usually difficult [1-3]. Different approaches, such as membrane separation, oxidation, flocculation, coagulation, and adsorption, have been proposed for the removal of these dyes [4-6].

Recently, nanoparticles have been widely investigated because of their potential applications such as information storage devices, optoelectronics [7], nanoelectronics [8], nanosensors [9-11], catalysts, microelectronics, and magnetic recording media [12]. Factors such as size distribution and morphology of the nanoparticles can affect their properties and applications [13-15]. The physical and chemical properties of copper oxide nanoparticles make them promising for applications such as solar energy conversion, gas sensors, batteries, catalysis, high-temperature superconductors, and antibacterial agents with low toxicity and low cost $[16,17]$.

In wastewater treatment, various adsorbents have been investigated for pollutant removal. Among them, activated carbon (AC) is the most extensively utilized adsorbent because of having various structural forms, chemical stability, low density, and large specific surface area [4]. This carbonaceous material with high porosity is widely utilized in

*Corresponding author: Azadeh Jafari Rad; E-mail: jafarirad.azadeh@gmail.com DOR: 20.1001.1.26765837.2020.2.3.6.6

https://doi.org/10.29252/jcc.2.2.6 This is an open access article under the CC BY license (https://creativecommons.org/licenses/by/4.0) water treatment processes to remove organic/inorganic pollutants [18$20]$ because of its tunable chemical and physical characteristics [21, 22] including modifiable surface, high surface reactivity, large surface area, and highly porosity with controllability [23]. Currently, activated carbons are mostly considered as a catalyst and mild reducing agent with a low cost. Thus, the development of low-cost effective carbons and other efficient material for contaminants removal from wastewater is necessary [24].

The effect of different parameters such as the $\mathrm{CuO} / \mathrm{AC}$ ratio, $\mathrm{pH}$, temperature, shaking rate, and contact time on the adsorption performance of this system has been studied in various scenarios. Tartrazine or trisodium (IUPAC name) is known as a typical synthetic, anionic dye with water solubility $[25,26]$. Tartrazine causes intolerance and allergic reactions, especially for those with aspirin intolerance and asthmatics. Therefore, it is required to treat the wastewater containing various concentrations of tartrazine prior to discharge [4, 27].

Tartrazine is an anionic, synthetic, water-soluble azo dye with yellow color, which consists of one carboxylic functional group, one azo $(\mathrm{N}=\mathrm{N})$, and two sulphonic groups. Tartrazine is widely utilized in pharmaceuticals (gels, pills, and capsules), cosmetics, and different food products (jellies, chewing gum, chips, alcoholic beverages, sodas, and cakes). Several side effects have been appeared to be caused by Tartrazine including allergic reactions, attention deficit disorder, hyperactivity in children, damage to DNA, and lethal asthma [28, 29].

Most studies have concentrated on removing one or two of these contaminants, while several contamination forms usually exist in drinking water. Therefore, the development of materials with the potential to remove several pollutants is extremely valuable, as it could suggest 
simpler and more cost-effective processes.

This research aimed to synthesize copper oxide nanoparticles on activated carbon and study its potential for the Tartrazine removal. The effect of contact time, $\mathrm{pH}$ and buffer type and size, adsorption value, time, and electrolyte concentration on color removal percentage was studied.

\section{Materials and Methods}

\subsection{Materials}

Tartrazine (Trisodium (4E)-5-oxo-1-(4-sulfonatophenyl)-4-[(4- sulfonatophenyl)hydrazono]-3-pyrazolecarboxylate; C.I., 19,140; with a molar mass of $543.40 \mathrm{~g} \mathrm{~mol} \mathrm{~L}^{-1}$ and chemical formula of $\mathrm{C}_{16} \mathrm{H}_{9} \mathrm{~N}$ ${ }_{4} \mathrm{Na}_{3} \mathrm{O}_{9} \mathrm{~S}_{2}$ was selected as an adsorbate. Fig. 1 shows the molecular structure of Tartrazine. Highly pure materials with the analytical grade were used that were obtained from Merck, Iran. The dye concentration was measured at $427 \mathrm{~nm}$. UV-Vis spectrophotometer was used to study the absorption performance. A $\mathrm{pH}$ meter was utilized to measure the $\mathrm{pH}$ value of the solution.

\subsection{Sample preparation}

$1 \mathrm{~g}$ of active carbon and $0.024 \mathrm{~g}$ of $\mathrm{Cu}\left(\mathrm{NO}_{3}\right)_{2} \cdot 3 \mathrm{H}_{2} \mathrm{O}$ was added to distilled water $(100 \mathrm{~mL})$ followed by stirring for $30 \mathrm{~min} .1 .85 \mathrm{~g}$ of $\mathrm{NaBH}_{4}$ was dissolved in distilled water $(50 \mathrm{~mL})$, and then $10 \mathrm{~mL}$ of this solution was added dropwise to the copper nitrate solution and stirred for $2 \mathrm{~h}$ at room temperature. The sediments were filtered, washed with distilled water, and dried at $80{ }^{\circ} \mathrm{C}$ for $10 \mathrm{~h}$ followed by grinding. To study the adsorption performance of CuO-modified AC, $10 \mathrm{~mL}$ Tartrazine solution and $2 \mathrm{~mL}$ of phosphoric acid buffer solution $(\mathrm{pH}=7)$ were dissolved in $100 \mathrm{~mL}$ of distilled water. $0.05 \mathrm{~g}$ of the adsorbent particles was added to the prepared solution and stirring was applied for $30 \mathrm{~min}$. $10 \mathrm{~mL}$ of the solution was centrifuged in determined intervals to measure the adsorption by a UV-vis spectrophotometer at $423 \mathrm{~nm}$ indicating the dye concentrations.

\subsection{Determination of PZC point}

For determination of zero charge point $\left(\mathrm{pH}_{\mathrm{pzc}}\right)$, solutions of the absorbent with the ratio of 1 to $1000(\mathrm{w} / \mathrm{v})$ with different initial $\mathrm{pH}$ values $\left(\mathrm{pH}_{\mathrm{i}}\right)$ were prepared using $0.01 \mathrm{M} \mathrm{HCl}$ or $\mathrm{NaOH}$. The dispersed solutions were stirred at ambient temperature for $24 \mathrm{~h}$ and the $\mathrm{pH}$ values of the final solutions $\left(\mathrm{pH}_{\mathrm{f}}\right)$ were then measured. The $\Delta \mathrm{pH}$ values that are the differences between the initial and final values of $\mathrm{pH}$ were plotted vs. $\mathrm{pH}_{\mathrm{i}}$, and the point at which the $\mathrm{pH}$ change was zero was reported as $\mathrm{pH}_{\mathrm{pzc}}$.

\subsection{Kinetic models}

During the physicochemical process of adsorption, the mass transfer of a solute occurs from the aqueous phase to the surface of an adsorbent. In this research, pseudo-first-order and pseudo-second-order kinetic<smiles></smiles>

Fig. 1. Molecular structure of Tartrazine models were used to study the Tartrazine adsorption mechanism onto copper oxide-modified AC. Equation 1 represents the Lagergren-first-order kinetic model [30]:

$\operatorname{Ln}\left(q_{1}-q_{t}\right)=L n q_{1}-k_{1} t$

where $\mathrm{q}_{1}$ denotes the Tartrazine amounts adsorbed at equilibrium $(\mathrm{mg} / \mathrm{g}), \mathrm{q}_{\mathrm{t}}$ represents the Tartrazine amounts adsorbed at time $\mathrm{t}(\mathrm{min})$, and the rate constant $\left(\mathrm{min}^{-1}\right)$ was represented by $\mathrm{k}_{1}$. The $\mathrm{k}_{1}$ value was obtained using the curve of $\ln \left(\mathrm{q}_{1}-\mathrm{q}_{\mathrm{t}}\right)$ vs. time. The following linear pseudo-second-order model [30] was also used for kinetic studies.

$t / q_{t}=1 / k_{2} q_{2}^{2}+t / q_{2}$

In this equation, the rate constant of the pseudo-second-order kinetic adsorption model is denoted by $\mathrm{k}_{2}$. The slope of the linear plots presenting the change of $t / q_{t}$ with time is $1 / q_{2}$ and the intercept value gives 1 / $\mathrm{k}_{2} \mathrm{q}_{2}{ }^{2}$.

\subsection{Adsorption isotherms}

The interaction between the adsorbents and adsorbates can be described in the equilibrium state. To fit the adsorption isotherm data, the Langmuir and Freundlich models were used. Selecting the best-fit model was done based on the linear regression correlation coefficient values $\left(\mathrm{R}^{2}\right)$. The assumptions of the Langmuir model are the adsorption in a monolayer and the absence of interaction between the molecules of the adsorbate. Equation 3 is the linear equation of Langmuir isotherm.

$C_{e} / q_{e}=\left(1 / q_{m}\right) K_{L}+C_{e} / q_{m}$

where $\mathrm{q}_{\mathrm{e}}$ represent the equilibrium adsorption amount $(\mathrm{mg} / \mathrm{g})$ and $\mathrm{C}_{\mathrm{e}}$ denotes the equilibrium concentration $\left(\mathrm{mg} \mathrm{L}^{-1}\right)$. The Langmuir constant and the theoretical maximum adsorption capacity are denoted by $\mathrm{K}_{\mathrm{L}}$ and $\mathrm{q}_{\mathrm{m}}$, respectively. There exists another model that describes the solutes adsorption from a liquid to the solid surface, which is known as the Freundlich model. In this model, it is assumed that different adsorption energies in several sites are involved. The Freundlich model follows the presented equation of:

$\operatorname{Ln} q_{e}=\operatorname{Ln} K_{F}+(1 / n) \operatorname{Ln} C_{e}$

In this equation, $\mathrm{C}_{\mathrm{e}}$ and $\mathrm{q}_{\mathrm{e}}$ are the equilibrium concentration of Tartrazine $\left(\mathrm{mg} \mathrm{L}^{-1}\right)$ and the adsorbed dye at equilibrium, respectively $(\mathrm{mg} / \mathrm{g})$. The adsorbate amount that is adsorbed on the surface for a unit equilibrium concentration is defined by the Freundlich constant of $\mathrm{K}_{\mathrm{F}}$, which is a distribution or adsorption coefficient. The Freundlich constant of $\mathrm{n}$ reveals how favorable the adsorption process is. All experiments were performed on the batch.

Mass balance equation determines the adsorption capacity in the adsorbents equilibrium. The equation is based on the assumption that the dye amount adsorbed on the adsorbent surface is equal to the amount of the removed adsorbate from the solution:

$q_{e}=V\left(C_{0}-C_{e}\right) / m$

where $\mathrm{C}_{0}, \mathrm{~m}$, and $\mathrm{V}$ denote initial adsorbate concentration $\left(\mathrm{mg} \mathrm{L}^{-1}\right)$, adsorbent weight $(\mathrm{g})$, and volume of aqueous solution $(\mathrm{L})$, respectively.

For evaluation of the removal efficiency, samples were studied after the flocculation/coagulation and sedimentation. In this regard, the apparent color and the concentration parameters of the yellow dye were characterized. All analyses were carried out based on standard methods and repeated three times for each sample. Equation 6 was employed to 
calculate the removal efficiency for each analyzed parameter.

Removal efficiency $\%=\left(\left(C_{i}-C_{f}\right) / C_{i}\right) \times 100$

In this equation, $\mathrm{C}_{\mathrm{i}}$ is the initial value of each parameter and $\mathrm{C}_{\mathrm{f}}$ is its final value.

\section{Results and discussion}

\subsection{Determination of PZC point}

One of the important properties for the surface of solids containing hydroxyl groups is the determination of the PZC point. PZC point is the $\mathrm{pH}$ of the surrounding liquid medium, at which the sum of the positive surface charges is in balance with the total negative surface charges and the surface charge density is zero. Determining the PZC point for nanoscale structures is more important because of the increase in surface-to-mass ratio in these particles; subsequently, their surface charge increases. The $\mathrm{pH}$ change vs. $\mathrm{pH}_{\mathrm{i}}$ is shown in Fig. 2. It is observed that at $\mathrm{pH}=7.1$, the $\mathrm{pH}$ change is zero, indicating that the adsorbent charge at this point is zero.

\subsection{PH effect}

To investigate whether the $\mathrm{pH}$ changes influence the contaminant removal and apparent color, the adsorption percentage was measured in

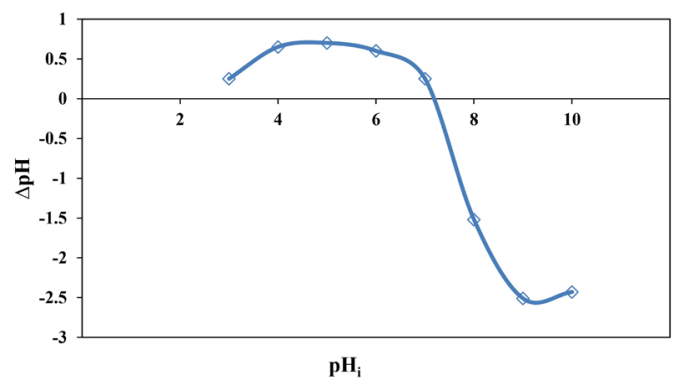

Fig. 2. $\mathrm{PH}$ changes vs. the initial $\mathrm{pH}$.

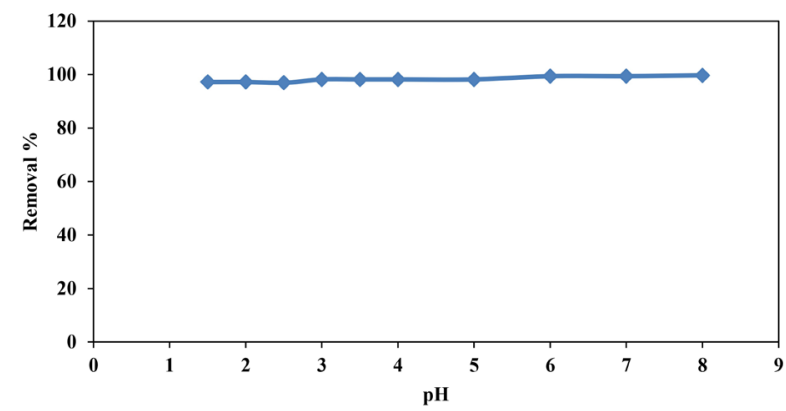

Fig. 3. Effect of $\mathrm{pH}$ on the Tartrazine removal. different $\mathrm{pH}$ of the solution. The adsorption percentages were measured by a UV-Vis spectrometer based on a plotted calibration curve with dye concentrations between 1 to $3 \mathrm{mg} \mathrm{L}^{-1}$. In Fig. 3, the effect of $\mathrm{pH}$ on the percentage removal of Tartrazine is illustrated. The results showed that the $\mathrm{pH}$ value does not significantly affect the dye removal, therefore $\mathrm{pH}=7$ was selected as optimal $\mathrm{pH}$ value.

\subsection{Effect of the adsorbent amount}

Modification of activated carbon with copper oxide nanoparticles affects its textural features including the decrease in diameter, pore volume, and surface area. To evaluate the influence of the absorbent amount on the removal efficiency, the adsorption was measured in solutions with different amounts of the adsorbent particles ranging from 0.001 to $0.15 \mathrm{~g}$. According to the observations, with an increase in the adsorbent amount, the amount of surface adsorption enhanced (Table 1). The dye removal reached the highest value in $0.05 \mathrm{~g}$ of adsorbent and the further increase in the dye concentration did not show significant changes in the adsorption. This might be due to the interaction of dye molecules with each other or other molecules in the solution preventing the complete removal of the contaminants. Fig. 4 shows the removal percentage vs. Tartrazine concentration.

\subsection{Effect of contact time and initial adsorbate concentration}

The influences of the initial adsorbate concentration of Tartrazine dye as well as contact time on the dve removal from the aqueous solu-

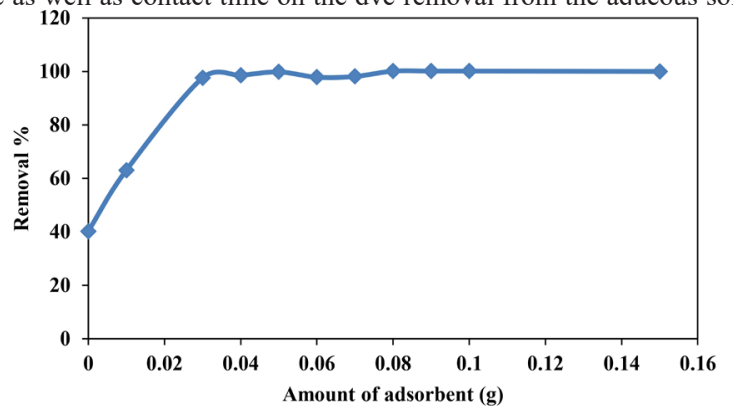

Fig. 4. Effect of $\mathrm{pH}$ on the Tartrazine removal.

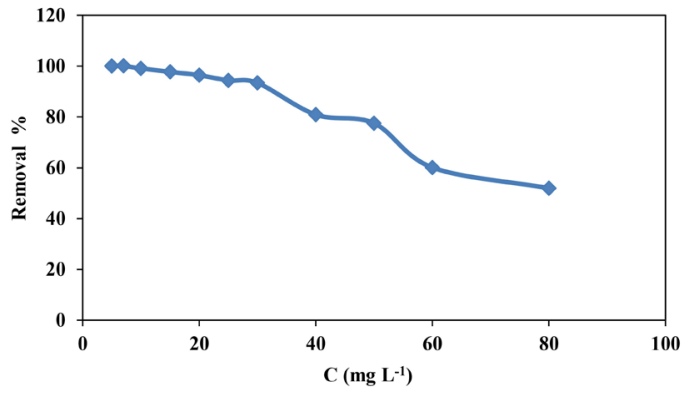

Fig. 5. Effect of the initial concentration of Tartrazine.

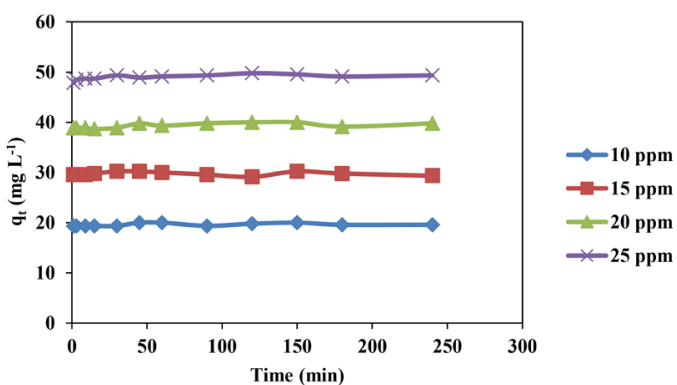

Fig. 6. Effect of initial Tartrazine contact time. 
(a)

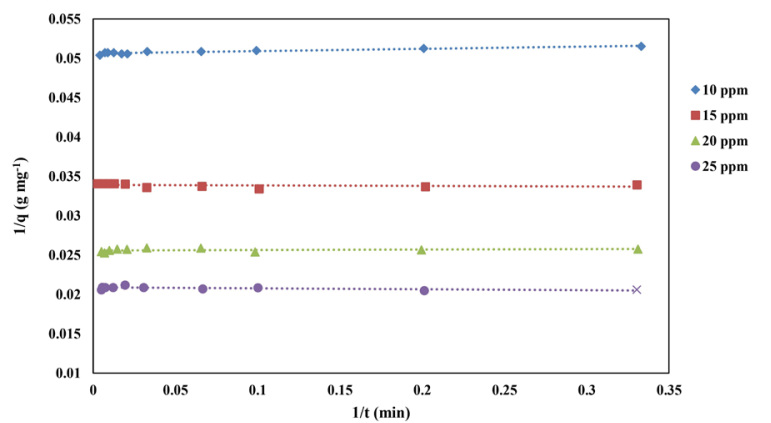

(b)

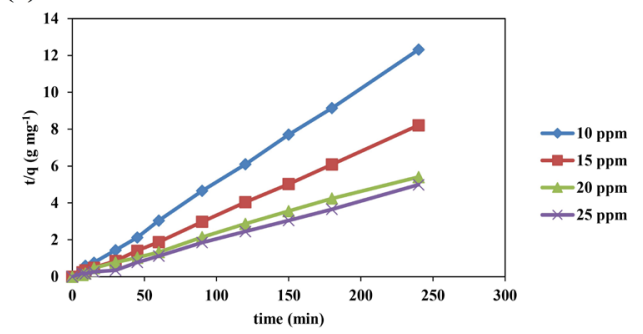

Fig. 7. Kinetic plots of adsorption: (a) pseudo-first-order and (b) pseudo-second-order.

tion were investigated. The results of these factors are presented in Fig. 5 and Fig. 6, respectively. According to Fig. 4, the increment of the initial concentration of the dye led to the reduction of Tartrazine removal. Principally, the initial concentration of Tartrazine can provide the driving force necessary for overcoming the resistance to the dye mass transfer between the solid surface of $\mathrm{AC}$ and aqueous phase. On the other hand, the interaction between the molecules of Tartrazine increases leading to the reduction of removal percentages. As seen in Fig. 6, the adsorption of the dye onto the modified $\mathrm{AC}$ was a relatively rapid process, revealing a high affinity between the surface of the absorbent particles and Tartrazine molecules. The accessibility of adsorption sites on the adsorbent surface was indicated by the high adsorption efficiency at an initial stage. The contact time does not significantly affect the dye removal. The required time for reaching an equilibrium was found to be $60 \mathrm{~min}$. Therefore, all subsequent experiments were conducted at the contact equilibrium time of $60 \mathrm{~min}$.

\subsection{Study of adsorption kinetics}

The kinetics of the Tartrazine adsorption onto copper oxide-modified (a)

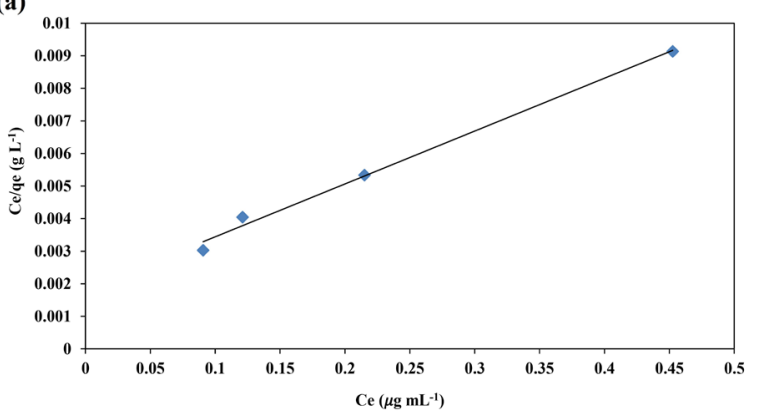

(b)

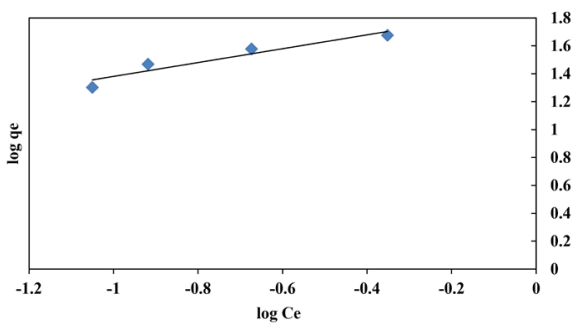

Fig. 8. Langumir (a) and Freundlich (b) isotherms of tartrazine adsorption.

AC surface was studied using the adsorption data for different initial dye concentrations. The adsorption kinetic curves are illustrated in Fig. 7 and Table 2 lists the parameters. According to the calculated data, $\mathrm{R}^{2}$ values of the pseudo-second-order model are close to 1 , revealing that the adsorption follows this model. Thus, this kinetic model can be used for the prediction of the dye uptake amount at various contact times and at equilibrium.

\subsection{Adsorption isotherms}

Considering the values of $\mathrm{C}_{\mathrm{t}}, \mathrm{C}_{0}$, solution volume of $0.1 \mathrm{~L}$, and the adsorbent weight of $0.05 \mathrm{~g}$, the values of $\mathrm{q}_{\mathrm{e}}$ for the dye concentrations of $15,25,35$, and $40 \mathrm{mg} \mathrm{L}^{-1}$ were obtained at the equilibrium time of $60 \mathrm{~min}$. The results are shown in Table 3. The $\mathrm{C}_{\mathrm{e}} / \mathrm{q}_{\mathrm{e}}$ diagram was then plotted against $\mathrm{C}_{\mathrm{e}}$ to obtain the parameters of the two equations, which are listed in Table 4. To show the degree of adsorption tendency to the adsorbent, a non-dimensional parameter called $\mathrm{R}_{\mathrm{L}}$ is used, which is calculated by Equation 7 obtained from the Langmuir equation.

$R_{L}=1 /\left(1+K_{L} C\right)$

where $\mathrm{C}$ denotes the initial concentration of the dye $\left(\mathrm{mg} \mathrm{L}^{-1}\right)$. If the $\mathrm{R}_{\mathrm{L}}$

Table 1.

Adsorbent value for different amounts of the adsorbent

\begin{tabular}{l|llllllllllll}
\hline $\begin{array}{l}\text { The amount of } \\
\text { adsorbent (g) }\end{array}$ & 0.001 & 0.010 & 0.030 & 0.040 & 0.050 & 0.060 & 0.070 & 0.080 & 0.090 & 0.100 & 0.150 \\
\hline $\begin{array}{l}\text { Removal } \\
\text { Percentage }\end{array}$ & 40.01 & 63.16 & 96.71 & 97.49 & 99.05 & 98.44 & 97.59 & 99.13 & 99.28 & 99.30 & 96.69 \\
\hline
\end{tabular}

Table 2.

Kinetic parameters of adsorption

\begin{tabular}{cccccc}
\hline \multirow{2}{*}{ Models } & $\begin{array}{c}\text { Parame- } \\
\text { ters }\end{array}$ & \multicolumn{5}{c}{ Initial concentration } \\
\hline \multirow{3}{*}{$\begin{array}{c}\mathbf{1 0} \\
\text { Pseudo-first- } \\
\text { order }\end{array}$} & $\mathrm{k}_{1}\left(\times 10^{3}\right)$ & 5.8 & 8.6 & 52.3 & 98.5 \\
& $\mathrm{q}_{1}$ & 15.98 & 22.70 & 35.23 & 42.36 \\
& $\mathrm{R}^{2}$ & 0.908 & 0.711 & 0.687 & 0.678 \\
Pseudo- & $\mathrm{k}_{2}\left(\times 10^{3}\right)$ & 61.7 & 88.5 & 214 & 310 \\
second-order & $\mathrm{q}_{2}$ & 19.88 & 29.76 & 42.91 & 49.50 \\
& $\mathrm{R}^{2}$ & 0.999 & 0.999 & 0.997 & 0.999 \\
\hline
\end{tabular}

Table 3.

The data calculated from Freundlich and Langmuir models from the adsorption isotherms

\begin{tabular}{cccccc}
\hline $\mathrm{C}_{0}\left(\mathrm{mg} \mathrm{L}^{-1}\right)$ & $\mathrm{C}_{\mathrm{e}}\left(\mathrm{mg} \mathrm{L}^{-1}\right)$ & $\mathrm{q}_{\mathrm{e}}\left(\mathrm{mg} \mathrm{g}^{-1}\right)$ & $\mathrm{C}_{\mathrm{e}} / \mathrm{q}_{\mathrm{e}}\left(\mathrm{g} \mathrm{L}^{-1}\right)$ & $\log \mathrm{C}_{\mathrm{e}}$ & $\log \mathrm{q}_{\mathrm{e}}$ \\
\hline 10 & 0.0903 & 19.81 & 0.0030 & -1.0443 & 1.2968 \\
15 & 0.1216 & 29.75 & 0.0040 & -0.9150 & 1.4735 \\
20 & 0.2122 & 39.57 & 0.0053 & -0.6732 & 1.5973 \\
25 & 0.4496 & 49.10 & 0.0091 & -0.3471 & 1.6910 \\
\hline
\end{tabular}


Table 4.

The calculated parameters of the adsorption isotherms

\begin{tabular}{cccc}
\hline \multirow{2}{*}{ Langmuir } & $\mathrm{q}_{\mathrm{m}}\left(\mathrm{mg} \mathrm{g}^{-1}\right)$ & $\mathrm{K}_{\mathrm{L}}\left(\mathrm{L} \mathrm{mg}^{-1}\right)$ & $\mathrm{R}^{2}$ \\
& 60.975 & 0.0018 & 0.9943 \\
\hline \multirow{2}{*}{ Freundlich } & $\mathrm{K}_{\mathrm{F}}\left(\mathrm{L} \mathrm{g}^{-1}\right)$ & $\mathrm{n}$ & $\mathrm{R}^{2}$ \\
& 80.612 & 1.9011 & 0.8957 \\
\hline
\end{tabular}

Table 5.

$\mathrm{R}_{\mathrm{L}}$ values for different initial concentrations of Tartrazine

\begin{tabular}{ccccc}
\hline $\mathbf{C}_{\mathbf{0}}$ & 10 & 15 & 20 & 25 \\
\hline $\mathbf{R}_{\mathbf{L}}$ & 0.9823 & 0.9737 & 0.9652 & 0.9569
\end{tabular}

value is greater than 1 , it reveals that surface adsorption has occurred under undesirable conditions. If $\mathrm{R}_{\mathrm{L}}=1$, it will indicate that the adsorption is linear. When the $R_{L}$ value is less than 1 and greater than zero, surface adsorption will occur under favorable conditions, and if the $R_{L}$ equals to 0 , the adsorption will be irreversible. The values of $R_{L}$ for the different initial concentrations are shown in Table 5. Based on the obtained $R_{L}$ values, surface adsorption has occurred under favorable conditions.

The linear form of Langmuir and Freundlich models was utilized to fit the adsorption isotherms (Fig. 8). The correlation coefficient of $\mathrm{R}^{2}$ indicates whether the isotherm equations are applicable for the description of the adsorption process. The higher linearity and $\mathrm{R}^{2}$ in the $\mathrm{C}_{\mathrm{e}} / \mathrm{q}_{\mathrm{e}} \mathrm{vs} . \mathrm{C}_{\mathrm{e}}$ curve (Fig. 8a) indicated that the Langmuir equation could be applied for fitting the experimental data and interpret the dye adsorption onto copper oxide-modified AC particles. It is worth noting that the theoretical value of $\mathrm{q}_{\mathrm{m}}$ was obtained close to the maximum adsorption capacities $\left(\mathrm{q}_{\mathrm{e}}\right)$ obtained from the experimental studies. Moreover, it is interesting to understand whether the adsorption of the dye is favorable or not. In the Freundlich model, when the n values are in the range of 2-10, the adsorption is good, while the values less than 1 show poor adsorption behavior. The values between 1 to 2 indicate moderately difficult adsorption characteristics. Based on the obtained values, the studied material is a good adsorbent for tartrazine. Surface heterogeneity or adsorption intensity is measured by the slope of $1 / \mathrm{n}$ in the range of 0 to 1 . A straight line with slope $1 / n$ is obtained from the curve of $\ln q_{e}$ vs. $\ln C_{e}$ (Fig. 8b). If the value gets closer to 0 , it indicates a more heterogeneous surface.

\section{Conclusions}

In this research, activated carbon was modified with copper oxide to absorb the Tartrazine dye from wastewater and the contributed mechanisms in the adsorption process were investigated. AC particles modified with copper oxide were found to be very efficient in the removal of Tartrazine dye. According to the batch experiments, the adsorption process was conducted rapidly, as maximum removal percentage of the dye obtained within 60 minutes of contact time for the initial dye concentration of $30 \mathrm{mg} / \mathrm{L}^{-1}$. Based on the equilibrium data related to the Freundlich and Langmuir models, the Langmuir isotherm appeared to be more concise for the description of the Tartrazine adsorption. The adsorption kinetics followed closely the pseudo-second-order kinetic model. Finally, the removal efficiency was found to be more than $98 \%$. Therefore, the modified AC particles can be a good candidate for the removal of Tartrazine from aqueous solutions.

\section{Acknowledgments}

The author thank the Research Committee of Islamic Azad University (Omidiyeh Branch) for financial support of this work.

\section{Conflict of Interest}

All authors declare no conflicts of interest in this paper.

\section{REFERENCES}

[1] D. Wang, N. Zhao, T. Wang, C. Zhuang, Y. Wang, B. Yang, Crystal Struc-ture, Spectroscopy and Photocatalytic Properties of a Co(II) Complex Based on 5-(1,2,4-triazol-1-yl)pyridine-3-carboxylic Acid, Crystals 10(2) (2020). [2] M. Golmohammadi, M. Honarmand, S. Ghanbari, A green approach to synthe-sis of $\mathrm{ZnO}$ nanoparticles using jujube fruit extract and their application in photo-catalytic degradation of organic dyes, Spectrochimica Acta Part A: Molecular and Biomolecular Spectroscopy 229 (2020) 117961.

[3] A. Tkaczyk, K. Mitrowska, A. Posyniak, Synthetic organic dyes as contami-nants of the aquatic environment and their implications for ecosystems: A review, Science of The Total Environment 717 (2020) 137222

[4] J. Goscianska, R. Pietrzak, Removal of tartrazine from aqueous solution by carbon nanotubes decorated with silver nanoparticles, Catalysis Today 249 (2015) 259-264.

[5] A. Kazemzadeh, H. Kazemzadeh, L. Bazli, Determination of $\mathrm{Hg}_{2}+$ by Diphenyl-carbazone Compound in Polymer Film, Composites and Compounds 1(1) (2019).

[6] H. Won Jang, A. Zareidoost, M. Moradi, A. Abuchenari, A. Bakhtiari, R. Pouri-amanesh, B. Malekpouri, A. Jafari Rad, Photosensitive nanocomposites: environ-mental and biological applications, Journal of Composites and Compounds 1(1) (2020).

[7] S. Saadi, B. Nazari, Submission Title: Recent Developments and Applications of Nanocomposites in Solar Cells: a Review, Composites and Compounds 1(1) (2019).

[8] A. Kazemzadeh, M.A. Meshkat, H. Kazemzadeh, M. Moradi, R. Bahrami, R. Pouriamanesh, Submission Title: Preparation of Graphene Nanolayers through Surfactant-assisted Pure Shear Milling Method, Composites and Compounds 1(1) (2019).

[9] L. Bazli, M. Siavashi, A. Shiravi, A Review of Carbon Nanotube/TiO2 Composite Prepared via Sol-Gel Method, Composites and Compounds 1(1) (2019).

[10] E. Asadi, A. Fassadi Chimeh, S. Hosseini, S. Rahimi, B. Sarkhosh, L. Bazli, R. Bashiri, A.H. Vakili Tahmorsati, A Review of Clinical Applications of Graphene Quantum Dot-based Composites, Composites and Compounds 1(1) (2019).

[11] V.S. Rizi, F. Sharifianjazi, H. Jafarikhorami, N. Parvin, L.S. Fard, M. Irani, A. Esmaeilkhanian, Sol-gel derived $\mathrm{SnO}_{2} / \mathrm{Ag}_{2} \mathrm{O}$ ceramic nanocomposite for $\mathrm{H} 2$ gas sensing applications, Materials Research Express 6(11) (2019) 1150g2.

[12] F. Sharifianjazi, M. Moradi, N. Parvin, A. Nemati, A.J. Rad, N. Sheysi, A. Abouchenari, A. Mohammadi, S. Karbasi, Z. Ahmadi, Magnetic $\mathrm{CoFe}_{2} \mathrm{O}_{4}$ nanopar-ticles doped with metal ions: a review, Ceramics International (2020).

[13] S. Muthukrishnan, A. Eswaran, Phytochemical and antimicrobial profile of nanobased liv-pro-09 polyherbal formulation.

[14] F.S. Jazi, N. Parvin, M. Rabiei, M. Tahriri, Z.M. Shabestari, A.R. Azadmehr, Effect of the synthesis route on the grain size and morphology of $\mathrm{ZnO} / \mathrm{Ag}$ nano-composite, Journal of Ceramic Processing Research 13(5) (2012) 523-526.

[15] F.S. Jazi, N. Parvin, M. Tahriri, M. Alizadeh, S. Abedini, M. Alizadeh, The relationship between the synthesis and morphology of $\mathrm{SnO}_{2}-\mathrm{Ag}_{2} \mathrm{O}$ nanocomposite, Synthesis and Reactivity in Inorganic, Metal-Organic, and Nano-Metal Chemistry 44(5) (2014) 759-764.

[16] J. Peternela, M.F. Silva, M.F. Vieira, R. Bergamasco, A.M.S. Vieira, Synthesis and Impregnation of Copper Oxide Nanoparticles on Activated Carbon through Green Synthesis for Water Pollutant Removal, Materials Research 21 (2018).

[17] A. Moghanian, F. Sharifianjazi, P. Abachi, E. Sadeghi, H. Jafarikhorami, A. Sedghi, Production and properties of $\mathrm{Cu} / \mathrm{TiO}_{2}$ nano-composites, Journal of Alloys and Compounds 698 (2017) 518-524.

[18] S. Periyasamy, I.A. Kumar, N. Viswanathan, Activated Carbon from Different Waste Materials for the Removal of Toxic Metals, in: M. Naushad, E. Lichtfouse (Eds.), Green Materials for Wastewater Treatment, Springer International Publish-ing, Cham, 2020, pp. 47-68.

[19] P.P. Bhave, D. Yeleswarapu, Removal of Indoor Air Pollutants Using Acti-vated Carbon-A Review, in: V. Sivasubramanian, S. Subramanian (Eds.) Global Challenges in Energy and Environment, Springer Singapore, Singapore, 2020, pp. 65-75.

[20] Z. Heidarinejad, M.H. Dehghani, M. Heidari, G. Javedan, I. Ali, M. Sillanpää, Methods for preparation and activation of activated carbon: a review, Environmen-tal Chemistry Letters 18(2) (2020) 393-415.

[21] K. Gong, X. Li, H. Liu, X. Cheng, D. Sun, Q. Shao, M. Dong, C. Liu, S. Wu, T. Ding, B. Qiu, Z. Guo, Residue metals and intrinsic moisture in excess sludge improve pore formation during its carbonization process, Carbon 156 (2020) 320328.

[22] C.H. Nguyen, H.N. Tran, C.-C. Fu, Y.-T. Lu, R.-S. Juang, Roles of adsorption 
and photocatalysis in removing organic pollutants from water by activated car-bon-supported titania composites: Kinetic aspects, Journal of the Taiwan Institute of Chemical Engineers 109 (2020) 51-61.

[23] F.S. Arakawa, Q.L. Shimabuku-Biadola, M. Fernandes Silva, R. Bergamas-co, Development of a new vacuum impregnation method at room atmosphere to produce silver-copper oxide nanoparticles on activated carbon for antibacterial applications, Environmental Technology (2019) 1-12.

[24] M. Ghaedi, A.M. Ghaedi, M. Hossainpour, A. Ansari, M.H. Habibi, A.R. Asghari, Least square-support vector (LS-SVM) method for modeling of methylene blue dye adsorption using copper oxide loaded on activated carbon: Kinetic and isotherm study, Journal of Industrial and Engineering Chemistry 20(4) (2014) 1641-1649.

[25] M.K.T. Al-Zain, Removal of Toxic Organic Compounds and Dyes from Water by Magnesium Oxide Nanostructure, Al-Azhar University-Gaza, 2019.

[26] K. Rovina, S. Siddiquee, S. Md Shaarani, An electrochemical sensor for the determination of tartrazine based on CHIT/GO/MWCNTs/AuNPs composite film modified glassy carbon electrode, Drug and Chemical Toxicology (2019) 1-11.
[27] K.G. Pavithra, S.K. P, J. V, S.R. P, Removal of colorants from wastewater: A review on sources and treatment strategies, Journal of Industrial and Engineering Chemistry 75 (2019) 1-19.

[28] N.A. Al-Shabib, J.M. Khan, M.S. Khan, M.S. Ali, A.M. Al-Senaidy, M.A. Alsenaidy, F.M. Husain, H.A. Al-Lohedan, Synthetic food additive dye "Tartra-zine" triggers amorphous aggregation in cationic myoglobin, International Journal of Biological Macromolecules 98 (2017) 277-286.

[29] G.A.P. Mateus, T.R.T. dos Santos, I.S. Sanches, M.F. Silva, M.B. de Andrade, M.P. Paludo, R.G. Gomes, R. Bergamasco, Evaluation of a magnetic coagulant based on $\mathrm{Fe}_{3} \mathrm{O}_{4}$ nanoparticles and Moringa oleifera extract on tartrazine removal: coagulation-adsorption and kinetics studies, Environmental Technology (2018) $1-16$.

[30] S. Sahnoun, M. Boutahala, C. Tiar, A. Kahoul, Adsorption of tartrazine from an aqueous solution by octadecyltrimethylammonium bromide-modified benton-ite: Kinetics and isotherm modeling, Comptes Rendus Chimie 21(3-4) (2018) 391-398. 